\title{
Extracellular Matrix Mimetic Peptide Scaffolds for Neural Stem Cell Culture and Differentiation
}

\author{
Busra Mammadov, Mustafa 0. Guler, and Ayse B. Tekinay
}

\begin{abstract}
Self-assembled peptide nanofibers form three-dimensional networks that are quite similar to fibrous extracellular matrix (ECM) in their physical structure. By incorporating short peptide sequences derived from ECM proteins, these nanofibers provide bioactive platforms for cell culture studies. This protocol provides information about preparation and characterization of self-assembled peptide nanofiber scaffolds, culturing of neural stem cells (NSCs) on these scaffolds, and analysis of cell behavior. As cell behavior analyses, viability and proliferation of NSCs as well as investigation of differentiation by immunocytochemistry, qRT-PCR, western blot, and morphological analysis on ECM mimetic peptide nanofiber scaffolds are described.
\end{abstract}

Keywords: Peptide nanofibers, Scaffolds, Self-assembly, Hydrogels, Neural stem cells

\section{Introduction}

Neural stem cells (NSCs) are the stem cells of the central nervous system (CNS), which are present in both embryonic and adult brain. In contrary to other neural cells of CNS, NSCs have proliferative ability. They demonstrate not only self-renewing ability but also potential to differentiate into neurons, astrocytes, and oligodendrocytes (1). However, NSCs are very low in number and are localized to very restricted areas in brain (such as dentate gyrus and subventricular zone in adult human brain), which make them insufficient to regenerate the brain after any neural degeneration. Transplantation of either NSCs or differentiated cells from NSCs is considered to be a promising approach for CNS regeneration (2). Obtaining NSCs for such a therapy has been the pitfall of this approach as they can only be obtained from adult cadavers or aborted fetuses, both of which can be considered as allotransplants bearing risk of immune rejection. In addition, use of fetal cells raises ethical concerns about such a therapy. Fortunately, iPSC-derived 
NSCs have recently been introduced, solving both the donor shortage problem and immune rejection risk, as they are the own cells of the patient (3). They have been proved to have similar selfrenewal and differentiation capacity to the NSCs isolated from CNS (4). Besides, generation of NSCs directly from fibroblasts is also found to be possible by skipping the iPSC step. These cells are even safer for clinical use as they are proved to have no teratogenic risk upon transplantation $(5,6)$.

Although it is promising to transplant NSCs to the damaged area of the brain, it is not as successful as desired when used alone. This is mainly due to the non-permissive environment in the degenerated area which inhibits regeneration (7). Hence, transplantation within a permissive scaffold, which supports adhesion and proliferation of NSCs or axonal extension by neurons differentiated from NSCs, would be a better alternative to transplanting NSCs alone.

Self-assembled peptide nanofibers are powerful tools for producing bioactive scaffolds that are tailored according to the demands of the specific cells. Peptide amphiphiles (PA), which are molecules consisting of a hydrophobic alkyl chain conjugated to a peptide sequence, can be used as building blocks of these scaffolds. Peptide part of the PA molecules usually contains an amino acid sequence containing $\beta$-sheet-prone amino acids such as valine or alanine along with some charged amino acids and an epitope sequence for bioactivity (8). Charged amino acids are important both for solubility of the peptide and for nanofiber formation. PA molecules of opposite charges come together by electrostatic interactions in aqueous environment along with the hydrophobic interactions of alkyl groups. Through these interactions, peptide nanofibers, that are $8-10 \mathrm{~nm}$ in diameter, are produced. These nanofibers are actually cylindrical micelles where hydrophobic tails are embedded in the nanofibers and hydrophilic peptide sequences containing the epitope remain on the periphery of the nanofibers. During formation of the nanofibers, water is trapped in the peptide nanofiber networks leading to formation of a hydrogel system. Physical structures of these nanofiber networks are quite similar to the structure of fibrous extracellular matrix $(9,10)$. Besides having similar structure to ECM, these scaffolds can be produced with similar bioactivity by incorporating short peptide sequences in the epitope region, which are derived from the cell surface receptor interacting domains of ECM proteins. RGDS (11), KRSR (12), YIGSR (13), DGEA (12), REDV (14), and $\operatorname{IKVAV~}(9,15)$ are some of these sequences that have been previously used to obtain bioactive peptide nanofiber scaffolds. IKVAV is a peptide sequence derived from laminin, and incorporation of this sequence in peptide nanofiber scaffolds has been shown to direct NSC differentiation into neurons rather than astrocytes or oligodendrocytes (15).

In this chapter, production of peptide nanofiber scaffolds from peptide amphiphile molecules, their characterization, and utilization 
for NSC culture and differentiation are described. Protocols for analyzing the effect of the scaffold on NSC viability and proliferation as well as analysis of the scaffold effect on differentiation are provided. Immunostaining of cell type-specific proteins along with qRT-PCR and western blot analysis is explained in detail. In addition, a method for quantitative analysis of morphological changes after differentiation is provided.

\section{Materials}

\subsection{Cell Culture}

2.2 Viability and Proliferation Tests

\subsection{Immunocyto- chemistry}

1. Serological pipettes (Axygen), 15 and $50 \mathrm{~mL}$ conical tubes (CAPP), sterile pipette tips (filtered tips are preferred, Expel), tissue culture flasks and plates (Corning).

2. NSC culture medium: KnockOut DMEM/F-12 medium supplemented with $1 \%$ GlutaMAX-I, $2 \%$ StemPro NSC SFM Supplement, $20 \mathrm{ng} / \mathrm{mL}$ bFGF and EGF (all from Invitrogen). It is stable for 4 weeks when stored in the dark at $4{ }^{\circ} \mathrm{C}$. Prepare $100 \mathrm{~mL}$ each time, and work in aliquots to avoid exposing it to $37^{\circ} \mathrm{C}$ multiple times.

3. NSC differentiation medium: Same with NSC culture medium except that it is not supplemented with bFGF and EGF.

4. PBS without calcium and magnesium.

5. Accutase (Invitrogen).

1. Alamar Blue reagent (Invitrogen).

2. Live/Dead Assay (Invitrogen).

3. Cell proliferation ELISA, Colorimetric BrdU assay (Roche).

1. $13 \mathrm{~mm}$ diameter, round glass coverslips (Thermo Scientific).

2. $4 \%$ paraformaldehyde (PFA) solution (16): Add 4 g PFA (see Note 1), 4 g sucrose, $10 \mathrm{~mL} 10 \times \mathrm{PBS}, 0.5 \mathrm{~mL} 1 \mathrm{M} \mathrm{MgCl}_{2}$,

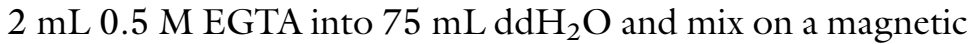
stirrer. Add $10 \mathrm{~N} \mathrm{NaOH}$ dropwise until solution clears. Then, adjust $\mathrm{pH}$ to 7.4 by dropwise addition of $6 \mathrm{~N} \mathrm{HCl}$, and adjust volume to $100 \mathrm{~mL}$ by adding $\mathrm{ddH}_{2} \mathrm{O}$. Aliquoted solution can be stored at $-20{ }^{\circ} \mathrm{C}$ until use. Heat is not preferred for dissolving PFA since higher temperatures can lead to generation of formic acid which results in increased background staining. Instead, $\mathrm{pH}$ transition is used to dissolve PFA in this protocol. $\mathrm{MgCl}_{2}$ along with EGTA is used to preserve cytoskeletal structure, and sucrose is used to maintain overall morphology during fixation.

3. $0.3 \%$ TritonX solution: Dissolve TritonX detergent in PBS to a final concentration of $0.3 \%(\mathrm{v} / \mathrm{v})$ on a magnetic stirrer until 
2.4 RNA Isolation and $q R T-P C R$

\subsection{Cell Lysate \\ Preparation and Western Blot}

you obtain a homogeneous solution. Solution can be stored at room temperature (RT).

4. Blocking solution: Prepare by adding $1 \%$ BSA (diluted from a $10 \%$ stock in PBS) and $10 \%$ normal goat serum into $0.3 \%$ TritonX solution. This solution is prone to contamination; thus prepare it fresh. $10 \% \mathrm{BSA}$ solution along with goat serum are stored at $-20{ }^{\circ} \mathrm{C}$ in $1 \mathrm{~mL}$ aliquots.

5. Primary antibody dilution solution: Prepare similarly to blocking solution except that final concentration of normal goat serum here is $3 \%$.

6. Secondary antibody dilution solution: Dilute $10 \%$ BSA stock solution to a final concentration of $1 \%$ in PBS.

7. TO-PRO-3 (Invitrogen) diluted solution: Dilute $1 \mathrm{mM}$ stock solution to $1 \mu \mathrm{M}$ final concentration in PBS.

8. ProLong Gold Antifade Mounting Medium (Invitrogen).

1. TRIzol (Invitrogen).

2. Chloroform.

3. Isopropanol.

4. Ethanol.

5. DNase/RNase free water (Gibco).

6. DNase/RNase-free microcentrifuge tubes and pipette tips.

7. Temperature-controlled centrifuge.

8. Primer sets for target genes and at least one housekeeping gene.

9. SuperScript ${ }^{\circledR}$ III Platinum ${ }^{\circledR}$ SYBR $^{\circledR}$ Green One-Step qRT-PCR Kit (Invitrogen).

10. A thermal cycler with real time analysis property and software (BioRad).

1. Lysis buffer: Prepare a $4 \times$ stock without protease inhibitor $(\mathrm{PI})$ cocktail. Dilute to $\mathrm{l} \times$ with $\mathrm{ddH}_{2} \mathrm{O}$, and add PI at a final concentration of $2 \%$ immediately before use. Prepare $4 \times$ lysis buffer by mixing $2 \mathrm{~mL}$ of $1 \mathrm{M}$ Tris- $\mathrm{HCl}, \mathrm{pH} 6.8$ (final concentration: $200 \mathrm{mM}$ ), $160 \mu \mathrm{L}$ of $0.5 \mathrm{M}$ EDTA, $\mathrm{pH} 8.0$ (final concentration: $8 \mathrm{mM}$ ), $4 \mathrm{~mL}$ of $10 \%$ SDS (final concentration: $4 \%$ ), $400 \mu \mathrm{L} \beta$-mercaptoethanol (final concentration: $4 \%$ ), and $3.2 \mathrm{~mL}$ of glycerol (final concentration: $32 \%$ ). Adjust volume to $10 \mathrm{~mL}$ by adding $\mathrm{ddH}_{2} \mathrm{O}$. Mix by vortexing. Aliquot the $4 \times$ lysis buffer, and store at $-20{ }^{\circ} \mathrm{C}$ until use.

2. Novex bis-tris 4-12\% acrylamide gels (Invitrogen).

3. Reagents and protein standards for Bradford protein assay (BioRad).

4. PVDF membrane (Thermo Scientific). 
5. Filter papers for blotting (BioRad).

6. Semi-dry blotting system (BioRad).

7. Anode I buffer: $0.3 \mathrm{M}$ Tris- $\mathrm{HCl}$ (pH 10.4), $10 \%$ methanol.

8. Anode II buffer: $25 \mathrm{mM}$ Tris- $\mathrm{HCl}$ (pH 10.4), $10 \%$ methanol.

9. Cathode buffer: $25 \mathrm{mM}$ Tris- $\mathrm{HCl}$ (pH 9.4), $10 \%$ methanol, $40 \mathrm{mM}$ glycine

10. Blocking solution: Dissolve nonfat dry milk (5 wt\%) in new TBS buffer, and add $0.1 \%(\mathrm{v} / \mathrm{v})$ Tween 20 . Mix on a magnetic stirrer until a homogeneous solution is obtained.

11. Tris-buffered saline (TBS): Prepare $10 \times$ TBS by mixing $200 \mathrm{~mL}$ of $\mathrm{l} \mathrm{M}$ Tris- $\mathrm{HCl}, \mathrm{pH} 7.5$ (final concentration: $200 \mathrm{mM}$ ) and $292.2 \mathrm{~g} \mathrm{NaCl}$ (final concentration: $5 \mathrm{M}$ ) on a magnetic stirrer. Adjust volume to $\mathrm{l} \mathrm{L}$ by adding $\mathrm{ddH}_{2} \mathrm{O}$. Dilute to $\mathrm{l} \times$ with $\mathrm{ddH}_{2} \mathrm{O}$. Both 10 and $\mathrm{l} \times$ buffers can be stored at room temperature.

12. TTBS: Prepare by mixing $100 \mathrm{~mL} 10 \times$ TBS, $0.5 \mathrm{~mL}$ Tween- 20

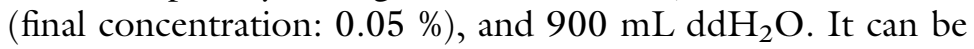
stored at room temperature.

13. New TBS: Prepare by mixing $10 \mathrm{~mL}$ of $1 \mathrm{M}$ Tris- $\mathrm{HCl}$, $\mathrm{pH} 7.5$ (final concentration: $0.01 \mathrm{M}$ ), $30 \mathrm{~mL}$ of $5 \mathrm{M} \mathrm{NaCl}$ (final concentration: $0.15 \mathrm{M}$ ), and $960 \mathrm{~mL}$ of $\mathrm{ddH}_{2} \mathrm{O}$. It can be stored at room temperature.

14. Novex Chemiluminescent Substrate (Invitrogen).

15. BioRad Imaging Station.

16. UREA buffer: $0.1 \mathrm{M} \mathrm{Na}_{2} \mathrm{HPO}_{4}, 0.01 \mathrm{M}$ Tris-HCl, $8 \mathrm{M}$ urea in $\mathrm{ddH}_{2} \mathrm{O}$, adjust $\mathrm{pH}$ to 8.0 .

\section{Methods}

\subsection{Peptide \\ Synthesis, \\ Purification, and Characterization}

Peptides are synthesized by a standard Fmoc-protected solid-phase peptide synthesis method. Synthesis, purification by highperformance liquid chromatography (HPLC), and characterization methods were previously described in detail (8).

1. After reverse-phase-high-performance liquid chromatography (RP-HPLC) purification of the peptide, evaporate acetonitrile by rotary evaporation and freeze-dry the peptide to obtain it in powder form.

2. Dissolve the peptide in desired concentration in $d_{d d} \mathrm{O}$. Mix by vortexing, and sonicate in ultrasound water bath until it completely dissolves. Check the $\mathrm{pH}$ of the peptide solution by using $\mathrm{pH}$ paper. Adjust the $\mathrm{pH}$ to 7 with $\mathrm{NaOH}$ or $\mathrm{HCl}$ solutions. 

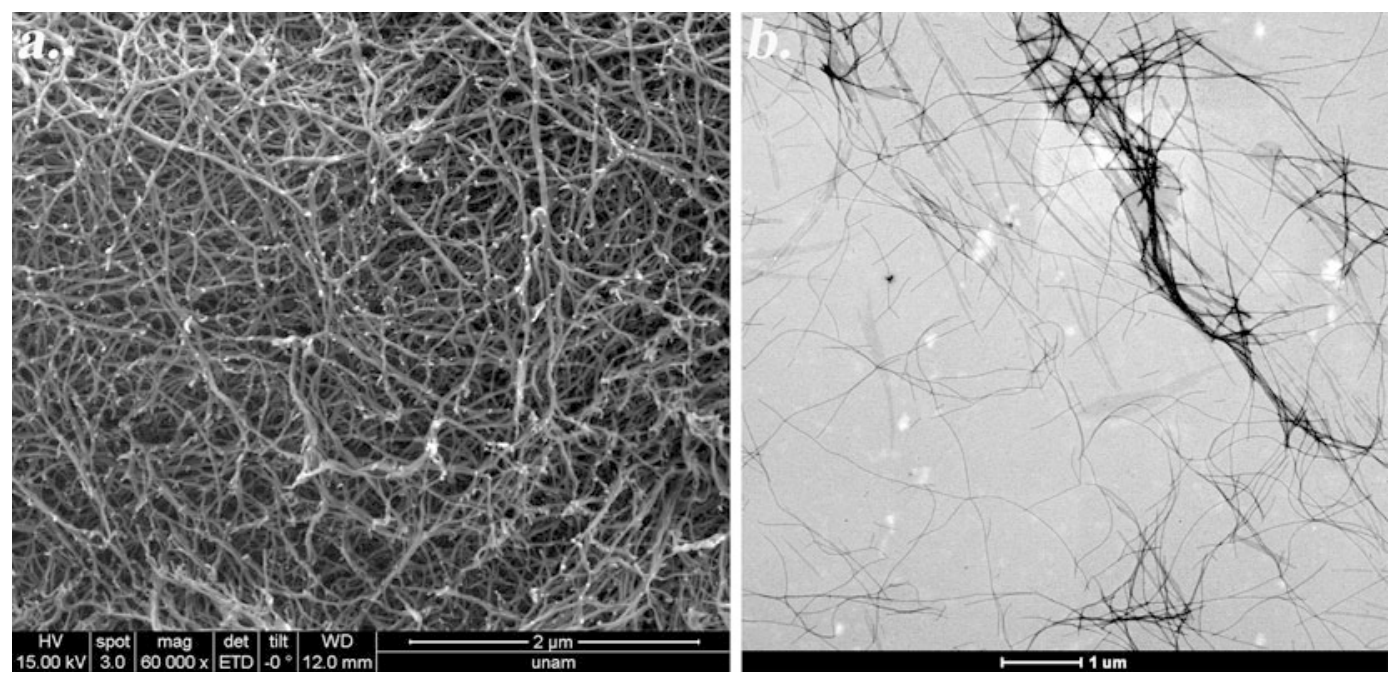

Fig. 1 (a) SEM image of the peptide nanofiber network, (b) TEM image showing individual peptide nanofibers

3. In order to analyze hydrogen bonding interactions, carry out circular dichroism (CD) measurements. Dissolve peptides to $2.5 \times 10^{-4} \mathrm{M}$ concentration as described above. Mix oppositely charged peptides in desired proportions, and mix by pipetting. Do not vortex in order not to disrupt the de novo-formed secondary structures. Detailed protocols are described here (8).

4. Stiffness of scaffold is an important physical property affecting the behavior of neural cells (17). In order to measure the stiffness of peptide nanofiber scaffolds, carry out rheological measurements. Prepare peptide gels of intended concentrations at a volume sufficient to fill the area of the upper plate. Prepare the gel on the lower plate, and incubate for at least for $10 \mathrm{~min}$ for gelation before measurement. Perform frequency sweep to determine storage modulus $\left(\mathrm{G}^{\prime}\right)$ and loss modulus $\left(\mathrm{G}^{\prime \prime}\right)$. The $\mathrm{G}^{\prime}$ value being higher than $\mathrm{G}^{\prime \prime}$ value indicates the gel behavior of the scaffold prepared. More detailed protocols for rheological analysis of peptide gels can be found here (8).

5. Characterize morphology of peptide nanofiber networks and peptide nanofibers individually by SEM and TEM imaging, respectively (Fig. 1). SEM imaging reveals the overall morphology of the scaffolds, while TEM is informative for investigating the morphology of individual fibers. It is possible to determine the diameter of peptide nanofibers from images taken by TEM. Detailed protocols of sample preparation and imaging parameters are explained here $(8,18)$.

\subsection{Preparation of Scaffolds and NSC Culture}

Peptide nanofiber scaffolds at physiological $\mathrm{pH}$ are produced by mixing oppositely charged peptide molecules dissolved in $\mathrm{ddH}_{2} \mathrm{O}$. Peptide nanofibers are formed by electrostatic interactions of 
oppositely charged side chains as well as hydrophobic interactions of the alkyl groups. By entrapment of water in between nanofiber networks during gelation, hydrogel scaffolds are produced.

1. Dissolve peptide powders in sterile $\mathrm{ddH}_{2} \mathrm{O}$ at intended concentrations (usually $0.1-1$ wt $\%$, see Note 2 ). Adjust $\mathrm{pH}$ to 7.4 as explained in Section 3.1, and sonicate in ultrasound water bath until they completely dissolve. UV sterilize peptide solutions for at least $30 \mathrm{~min}$.

2. For peptide nanofiber gel formation, add one of the oppositely charged peptide solutions to the well and then add the second solution via mixing with the pipette tip (with a swirling motion). A total volume of $300 \mu \mathrm{L}$ is enough for 24-well plate wells. You can adjust the volume for larger or smaller surfaces accordingly. While preparing gels, consider the final charge of the scaffold and mix two peptides in proper ratios accordingly. An optimization for the charge might be required to obtain optimal bioactivity of the scaffold.

3. After coating of wells with peptide gels, incubate the plate at $37{ }^{\circ} \mathrm{C}$ for $30 \mathrm{~min}$ to $\mathrm{l} \mathrm{h}$ for gelation to proceed and dry overnight under sterile conditions in a laminar flow hood. This step is carried out to evaporate water in the scaffold and obtain a nanofibrous network coating of the culture well surface. This network swells again with the culture medium and forms a very thin layer of gel beneath cells.

4. UV sterilize the peptide nanofiber-coated plate for at least $1 \mathrm{~h}$.

5. Seed NSCs at a density of $5 \times 10^{4}$ cells $/ \mathrm{cm}^{2}$ in $500 \mu \mathrm{L} /$ well for 24-well plate (see Note 3 ). You can adjust the volume for larger or smaller surfaces accordingly. After seeding, gently swirl the plate with your hand to obtain a homogeneous distribution of cells. Note that this protocol describes adherent culture of NSCs, not suspension culture as in the form of neurospheres. Incubate the plate at $37{ }^{\circ} \mathrm{C}, 5 \% \mathrm{CO}_{2}$ in a humidified incubator. Change medium every 3 days.

\subsection{Analysis of NSC Behavior on Scaffolds}

3.3.1 Viability
Viability of the cells can be determined by either Alamar Blue Test or Live/Dead Assay as described below. Both detect live cells through metabolic activity of live cells, while Live/Dead Assay also detects dead cells by plasma membrane disintegrity. Detecting dead cells along with live cells is advantageous in that it directly provides data related to any cytotoxic effect leading to cell death. When the number of living cells is observed to be reduced by Alamar Blue, where only live cells are detected, it is not easy to understand if such a drop is caused by decreased cell proliferation or cell death. Detecting dead cells at the same time becomes advantageous in such a case.

Alamar Blue $(\mathrm{AB})$ Test is a metabolic activity-based viability test. Active ingredient of $\mathrm{AB}$ reagent is resazurin, which is blue in color 
and non-fluorescent. Resazurin can readily enter into cells (it is cell permeable), and upon entering, it is reduced to resorufin by active metabolism of live cells. Resorufin is pink and fluorescent. The amount of resorufin produced and absorbance/fluorescence measured are directly proportional to the number of living cells.

1. Coat the wells of a 96-well plate with peptide nanofibers as described in Section 3.2. Prepare peptide nanofiber-coated wells to be used as blank as well. This is to avoid any background absorbance that might be caused by peptide nanofibers.

2. Seed cells at a density of $5 \times 10^{3}$ to $2 \times 10^{4}$ cells/well depending on the incubation time prior to viability measurement. Too low cell density leads to insufficient color development leading to unreliable results, while too high cell density leads to contact inhibition as well as cell death which again results in unreliable data. Add medium without cells to wells that will be used as blank.

3. At the time of analysis (usually in between 24 and $72 \mathrm{~h}$ ), discard medium from wells and add $110 \mu \mathrm{L}$ of fresh medium with Alamar Blue reagent $(100 \mu \mathrm{L}$ medium $+10 \mu \mathrm{L} \mathrm{AB} /$ well $)$. $10 \mu \mathrm{L}$ of $\mathrm{AB}$ can also be added directly to medium over cells without discarding the medium, but in the case of long culture periods, non-even evaporation from wells might lead to some inconsistency. Hence, it is better to discard all medium and add same amount to all wells. This step should be carried out at dark (see Note 4).

4. Incubate the plate in a $\mathrm{CO}_{2}$ incubator $\left(37{ }^{\circ} \mathrm{C}, 5 \% \mathrm{CO}_{2}\right)$ for 2-4 h, depending on cell density. Color change from blue to pink can be tracked to determine the time of measurement.

5. Measure absorbance at $570 \mathrm{~nm}$ (reference $\lambda: 600 \mathrm{~nm}$ ). Alternatively, fluorescence can also be measured (excitation: $560 \mathrm{~nm}$, emission: $590 \mathrm{~nm}$ ).

Live-Dead Assay

Live-Dead Assay is a viability test which is used to detect live cells as well as dead cells. This assay is based on esterase activity of live cells and loss of plasma membrane integrity of dead cells. Calcein AM is a cell-permeant, non-fluorescent molecule which is cleaved by intracellular esterases upon entering cells. Calcein formed after esterase cleavage is well retained in live cells (it is cell impermeant) and gives an intense green fluorescence by which live cells can be detected. Dead cells are distinguished by ethidium homodimer staining. Ethidium is excluded by plasma membrane in live cells, while it is retained in dead cells due to disintegrity of plasma membrane. Dead cells can be detected by red fluorescence of ethidium homodimer dye.

1. Coat the wells of a 96-well plate with peptide nanofibers as described in Section 3.2. 
2. Seed cells at a density of $5 \times 10^{3}$ to $2 \times 10^{4}$ cells/well depending on the time at which viability will be determined. Too low density leads to insufficient cell number in images leading to statistically unreliable results, while too high cell density leads to difficulties in distinguishing cell borders which again results in unreliable data.

3. At the time of analysis (usually in between 24 and $72 \mathrm{~h}$ ), centrifuge the plate at $650 \times g$ for $5 \mathrm{~min}$ in a centrifuge with a plate rotor. This step is essential to detect dead cells that usually detach and float in the medium. If not centrifuged, they will be discarded in the next step and will not be detected.

4. During centrifugation, prepare calcein + ethidium working solution by diluting calcein and ethidium to a final concentration of 2 and $4 \mu \mathrm{M}$, respectively, in PBS. Since $200 \mu \mathrm{L} /$ well will be used, prepare total volume according to the number of wells in the experiment. This step should be carried out in the dark to avoid fading of ethidium dye.

5. After centrifugation, discard medium over cells and add PBS slowly avoiding to detach cells. Carry out a brief (1-2 min) centrifugation at $650 \times \mathrm{g}$. PBS wash is carried out to remove any serum esterase that cleaves calcein and leads to nonspecific background fluorescence.

6. After PBS wash, add $200 \mu \mathrm{L} /$ well calcein+ethidium working solution (prepared in step 4) and incubate the plate for $30 \mathrm{~min}$ at room temperature (RT) in the dark.

7. After incubation, take merged images of calcein-stained live cells (green) and ethidium-stained dead cells (red) immediately by using an inverted fluorescent microscope. Take at least five random images/well.

8. Count the number of live and dead cells with Image J (Plugin: Cell Counter). Determine the $\%$ of live and dead cells on each substrate. Fluorescence of ethidium and calcein can also be measured alternatively as described in the product's manual. However, ethidium nonspecifically adheres to peptide nanofibers and produces high background due to which fluorescence measurement is not preferred. Dead cells are stained more intensely than the background and can be distinguished in images taken for counting.

3.3.2 Proliferation Test (BrdU Assay)
Stem cells, including NSCs, proliferate in culture. NSCs differentiate into neurons, astrocytes, or oligodendrocytes which are all nonproliferating cells. Hence, upon induction of differentiation a reduction in proliferation might indicate differentiation. However, this should not be used as the only data for verification of differentiation, since NSCs can also lose their proliferative ability due to cell senescence at later passage numbers. BrdU assay is commonly used for detection of proliferation. BrdU is a thymine analog, and it is incorporated into newly synthesized DNA in dividing cells; BrdU 
levels measured by ELISA are directly proportional to the number of proliferating cells.

1. Coat the wells of a 96-well plate with peptide nanofibers as described in Section 3.2. Prepare peptide nanofiber-coated wells to be used as blank as well. This is to avoid any background absorbance that might be caused by peptide nanofibers.

2. Seed cells at a density of $5 \times 10^{3}$ to $2 \times 10^{4}$ cells/well depending on the time at which proliferation will be determined. Too low density leads to insufficient color development leading to unreliable results, while too high cell density leads to contact inhibition as well as cell death which again results in unreliable data. Add medium without cells to wells that will be used as blank.

3. 2-24 h (depending on cell density and doubling time of cells) prior to the detection, discard medium over cells and add $100 \mu \mathrm{L}$ of fresh medium with $10 \mu \mathrm{M}$ BrdU reagent. $10 \mu \mathrm{L}$ of BrdU from stock can also be added directly to medium over cells without discarding the medium, but in case of long culture periods, non-even evaporation from wells might lead to some inconsistency. Hence it is better to discard all medium and add same amount to all wells. Incubate cells under standard cell culture conditions until the analysis (2-24 h later).

4. Discard the medium over cells by tapping or suction. The assay can be interrupted at this step to continue later. Dried cells can be stored for up to 1 week at $2-8{ }^{\circ} \mathrm{C}$ until analysis.

5. Fix cells by adding $200 \mu \mathrm{L} /$ well fixation solution provided in the kit, and incubate for $30 \mathrm{~min}$ at RT.

6. Remove fixation solution by flicking off and tapping. Add $100 \mu \mathrm{L} /$ well peroxidase-labelled BrdU antibody working solution (1:100 diluted from stock), and incubate for $90 \mathrm{~min}$ at RT.

7. Discard antibody solution by flicking off, and rinse wells with $200 \mu \mathrm{L} /$ well PBS three times.

8. Discard PBS by tapping, and add $100 \mu \mathrm{L} /$ well peroxidase substrate. Incubate at RT until color development is sufficient for detection (5-30 min). Measure absorbance at $372 \mathrm{~nm}$ (reference $\lambda: 492 \mathrm{~nm})$. Repeated measurements can be done in order to determine the optimal time of measurement.

3.4 NSC

Differentiation and Analysis of Differentiation
Forty-eight hours after seeding cells on peptide nanofiber scaffolds in NSC culture medium, discard the medium over cells and add NSC differentiation medium. Note that this medium is suitable for spontaneous differentiation of NSCs into neurons, astrocytes, and oligodendrocytes. Such an experiment is useful to determine the effect of the scaffold bioactivity in cell fate. If differentiation into a 
Table 1

Markers commonly used for analysis of cell fate after NSC differentiation

3.4.1 Immunocytochemistry

\begin{tabular}{lll}
\hline Cell type & Markers & Reference \\
\hline NSC & Nestin & $(19)$ \\
\hline Neuron & Map2, $\beta$-III-tubulin & $(20-22)$ \\
Astrocyte & GFAP & $(23)$ \\
Oligodendrocyte & GalC & $(24)$ \\
\hline
\end{tabular}

specific cell type is desired, additional growth factors should be included in the differentiation medium.

Immunostaining against specific markers of NSCs, neurons, astrocytes, and oligodendrocytes is a powerful method in analysis of spontaneous differentiation as it allows to determine which cell fate is more dominantly directed by the scaffold. Most commonly used markers for this analysis are shown in Table 1 .

1. For immunostaining, coat peptide nanofibers on $13 \mathrm{~mm}$ glass slides placed in 24-well plates, and culture and differentiate NSCs on these surfaces.

2. At the intended time point for analysis, discard the medium over cells and wash wells with PBS $(750 \mu \mathrm{L} /$ well $)$. Be careful not to detach cells in this step.

3. Fix cells with prewarmed $4 \%$ paraformaldehyde, $500 \mu \mathrm{L} /$ well for $15 \mathrm{~min}$ at RT.

4. Permeabilize cells with $500 \mu \mathrm{L} /$ well $0.3 \%$ TritonX for $15 \mathrm{~min}$ at RT. Slowly mix on shaker.

5. Wash with $750 \mu \mathrm{L} /$ well PBS for 5 min three times on shaker.

6. Add $500 \mu \mathrm{L} /$ well blocking solution, and incubate for $\mathrm{l} \mathrm{h}$ at RT. Slowly mix on shaker.

7. Add $100 \mu \mathrm{L} /$ well diluted primary antibody (see Note 5 for co-staining), seal the plate with parafilm, and incubate overnight at $4{ }^{\circ} \mathrm{C}$ on a shaker at slow rate (a nutator/rocking shaker is preferred). Next day, continue with an additional 30 -min to $\mathrm{l}$-h incubation at RT on shaker. For samples that will be used as negative control of staining, add primary antibody dilution solution described in Section 2.3 instead of primary antibody.

8. Wash with $750 \mu \mathrm{L} /$ well $0.3 \%$ TritonX for 5 min on shaker.

9. Wash with $750 \mu \mathrm{L} /$ well PBS for 5 min on shaker.

10. Add $100 \mu \mathrm{L} /$ well diluted secondary antibody that is conjugated with a fluorescent dye for detection. Incubate for $1 \mathrm{~h}$ at RT on a shaker at slow rate (a nutator/rocking shaker is preferred). 
3.4.2 RNA Isolation and $q R T-P C R$

RNA Isolation
Starting from this step work in the dark in order to avoid fading of fluorescence.

11. For nuclear staining, add $300 \mu \mathrm{L} /$ well TO-PRO-3 (1 $\mu \mathrm{M}$ final concentration) and incubate at RT for $15 \mathrm{~min}$ (see Note 6 for other nuclear staining options).

12. Wash with $750 \mu \mathrm{L} /$ well PBS for 5 min three times on shaker.

13. Wash with $750 \mu \mathrm{L} /$ well $\mathrm{ddH}_{2} \mathrm{O}$ for 5 min on shaker. This step is essential to avoid salt crystals that form during drying due to the remaining PBS.

14. Label slides properly, and add one drop of ProLong Gold Antifade Mounting Medium onto each slide avoiding bubbles.

15. Remove cover slip from well, invert, and put on the mounting solution on the slide. Avoid making air bubbles during this step.

16. Let the cover slip dry, and seal the edges with nail polish. Slides can be stored in the dark at $4^{\circ} \mathrm{C}$ for at least a couple of months.

17. Take images with a fluorescent/confocal laser scanning microscope.

All plastic materials and solutions used should be RNase free, and experiments should be carried out under class I laminar flow hood.

RNA isolation from low cell numbers is not efficient, so it is better to carry out differentiation in 6-well plates for this experiment. Use cold reagents (stored at $4^{\circ} \mathrm{C}$ ), and carry out centrifugation steps at $4{ }^{\circ} \mathrm{C}$ in order to avoid RNA degradation.

1. Discard medium from wells, and add $1 \mathrm{~mL} /$ well TRIzol. Carry out this step in a fume hood as TRIzol is toxic. Swirl the plate for efficient distribution of TRIzol through wells, and collect cell lysates in $1.5 \mathrm{~mL}$ labelled microcentrifuge tubes. After this step, samples can be stored at $-80{ }^{\circ} \mathrm{C}$ until RNA isolation.

2. Add $200 \mu \mathrm{L} /$ tube chloroform, shake tubes vigorously for $15 \mathrm{~s}$, and incubate for 2-3 min at RT.

3. Centrifuge samples at $21,500 \times g$ for $17 \mathrm{~min}$. After centrifugation, three layers with pink, white, and clear colors appear from the bottom to top. Transfer $500 \mu \mathrm{L}$ of the upper (clear) phase into a new tube for each sample trying not to disturb bottom layers.

4. Add $500 \mu \mathrm{L} /$ tube isopropanol, and mix by inversion 15 times. Incubate for $10 \mathrm{~min}$ at RT.

5. Centrifuge samples at $6,100 \times g$ for $12 \mathrm{~min}$. Discard supernatant, and add $1 \mathrm{~mL}$ of $75 \% \mathrm{EtOH}$. Do not dissolve the pellet; just detach it from the tube wall. 
6. Centrifuge samples at $6,100 \times g$ for $8 \mathrm{~min}$. Discard supernatant, and add $1 \mathrm{~mL}$ pure EtOH. Do not dissolve the pellet; just detach it from the tube wall.

7. Centrifuge samples at $6,100 \times g$ for $8 \mathrm{~min}$. Discard supernatant, and air-dry pellets for 3-5 min. Do not overdry as it reduces solubility of RNA in water. Add $30 \mu \mathrm{L} /$ tube DNase/ RNase-free water, and dissolve the pellet by pipetting.

8. Measure RNA concentration and absorbance ratios of 260/ 280 and 260/230 $\mathrm{nm}$ at Nanodrop. 260/280 ratios of 1.9-2.1 and 260/230 ratios of 2-2.3 are acceptable for use of RNA in qRT-PCR. Isolated RNA should be stored at $-80{ }^{\circ} \mathrm{C}$ until use.

qRT-PCR

For analysis of expression of marker genes, Pfaffl method is used for analysis of qRT-PCR results where primer efficiencies are also considered. We carry out cDNA synthesis and amplification of cDNAs in one reaction by using SuperScript ${ }^{\circledR}$ III Platinum ${ }^{\circledR}$ SYBR $^{\circledR}$ GreenOne-Step qRT-PCR Kit (Invitrogen), which is a conventional and time saving method. The below protocol is for the use of this method.

1. Design primers specific for the target genes. Try to select primers from exon-exon boundaries so that the DNA cannot be amplified (due to the long intron sequence involved, which is not present in RNA). If not possible, DNase treatment should be carried out to avoid amplification of DNA besides RNA.

2. Before expression analysis, optimize annealing temperature for primers. After that, determine primer efficiency by carrying out qRT-PCR with serial dilutions of RNA. Plot a standard curve with the Ct values ( $y$-axis) and RNA concentrations ( $x$-axis), and determine the slope of the curve. Efficiency should be in the range of $90-110 \%$ for reliable PCR results. Efficiency $(E)$ can be calculated by using the formula $E=10^{(-1 / \text { slope })}-1$.

3. Carry out qRT-PCR using primers for target genes as well as those for housekeeping genes. From $\mathrm{Ct}$ values obtained, perform a gene expression analysis by normalizing the results to those of housekeeping genes. You can now compare the expression between different experimental groups.

3.4.3 Cell Lysate Preparation and Western Blot
In order to obtain enough protein amount in cell lysate, using high cell numbers (at least 1.5-2 $\times 10^{5}$ cells) is essential. Hence, it is better to carry out differentiation in 6-well plates for this experiment. During cell lysate preparation from cells cultured on uncoated surfaces, adding lysis buffer directly to the well and scraping is a conventional method. However, for peptide nanofiber-coated surfaces, this method is not suitable as peptide scaffold is also collected 
and contributes to the protein amount detected during protein assay. This leads to confusion in understanding the total protein amount obtained from cells. For this reason, prefer to detach cells enzymatically and lyse them later. For blotting, we prefer to use semidry blotting by using Bio-Rad's equipment, and the below protocol is optimized for this method.

1. Detach cells by using conventional trypsin detachment method. Since cells might adhere to peptide scaffolds very strongly, they might not detach with only trypsin treatment. If you have problems in detaching cells by this method, you can try 1:1 mixture of trypsin (0.25\% trypsin-EDTA):collagenase (1\%). Incubate cells with this mixture for $30 \mathrm{~min}$ at $37^{\circ} \mathrm{C}$, and observe every 10 min under microscope after tapping to help in detachment. Almost $90 \%$ of cells detach with this method from the surfaces where cells adhere very strongly.

2. After detaching cells, centrifuge at $650 \times g$ for 5 min to obtain cell pellet. Dissolve the pellet in PBS, and centrifuge again.

3. Discard the PBS, and resuspend the pellet in 50-100 $\mu \mathrm{L}$ lysis buffer depending on the pellet size (see Section 2.5).

4. Incubate samples on ice for $30 \mathrm{~min}$. Vortex every $10 \mathrm{~min}$.

5. Sonicate samples on ice with a probe sonicator for 15-30 s.

6. Heat samples to $95{ }^{\circ} \mathrm{C}$ for $5 \mathrm{~min}$, and cool on ice. This step is essential to denature DNA, which causes viscosity in samples. Samples can be stored at $-80{ }^{\circ} \mathrm{C}$ after this step until use.

7. Determine the total protein amount in cell lysates by a method of your choice. We use Bradford Assay in our laboratory. Take care that the assay you choose does not interfere with the components of the lysis buffer and give false-positive results.

8. Load samples $(30-100 \mu \mathrm{g})$ and molecular weight marker to 4-12\% commercial gels for SDS-PAGE, and run the gel according to the manual provided with the gel. In order to check that blotting occurs properly and your antibodies work perfectly, you can load a positive control to one of the wells. Brain lysate can be used for this purpose as it contains all the neural marker proteins (see Note 7 for preparation of brain lysate).

9. For blotting, cut the PVDF membrane and extra thick filter papers to the dimensions of the gel. Three pieces of filter papers are required for one gel.

10. Equilibrate the gel and membrane in ice-cold transfer buffers (see Section 2.5) as described in Table 2.

11. Assemble the blotting unit, and place the filter papers, gel, and membrane according to Table 2 . The filter paper which was wet 
Table 2

Equilibration of filter papers, gel, and membrane before blotting

\begin{tabular}{|c|c|c|}
\hline $\begin{array}{l}\text { Layer starting } \\
\text { from the bottom }\end{array}$ & Material & Equilibration \\
\hline 1 & Filter paper & Wet with anode buffer I \\
\hline 2 & Filter paper & Wet with anode buffer II \\
\hline 3 & $\begin{array}{l}\text { PVDF } \\
\text { membrane }\end{array}$ & $\begin{array}{l}15 \text { min with methanol, } 2 \text { min } \\
\text { with } \mathrm{ddH}_{2} \mathrm{O}, 5 \mathrm{~min} \text { with } \\
\text { anode II on shaker }\end{array}$ \\
\hline 4 & Gel & 15 min with anode II \\
\hline 5 & Filter paper & Wet with cathode buffer \\
\hline
\end{tabular}

with cathode buffer will be at the top. Roll out air bubbles at every layer by using a glass pipette.

12. Carry out blotting at $14 \mathrm{~V}$ for $30 \mathrm{~min}$.

13. After blotting, place the membrane in blocking solution (see Section 2.5) and incubate for $2 \mathrm{~h}$ at RT, shaking slowly.

14. Discard blocking solution, and add primary antibody diluted in blocking solution. Incubate overnight at $4{ }^{\circ} \mathrm{C}$, shaking slowly. Next day, incubate at RT for $30 \mathrm{~min}$ to $1 \mathrm{~h}$.

15. Wash with blocking solution for $20 \mathrm{~min}$ at RT with shaking.

16. Add secondary antibody diluted in blocking solution. Incubate for $45 \mathrm{~min}$ at RT, shaking slowly.

17. Wash membrane with TTBS for 5 min twice and TBS for 5 min twice, with shaking.

18. Wash membrane with $\mathrm{ddH}_{2} \mathrm{O}$ for $5 \mathrm{~min}$.

19. Prepare substrate (Novex Chemiluminescent Substrate) immediately before use by mixing Reagent $A$ and Reagent $B$ in 1:1 ratio. It is essential to warm substrate reagents to RT before use. Work in a darkroom from this point forward.

20. Add substrate on the membrane, and incubate for $1 \mathrm{~min}$. Use substrate volume enough to cover the surface of the membrane.

21. Image the membrane with BioRad imaging station, VersaDoc software by selecting Blotting, "Chemiluminescence, UltraHigh Sensitivity" from the software with 600 s exposure time.

3.4.4 Analysis of Neurite Outgrowth
Neurite outgrowth is an indication of neuron's response to axon guidance cues provided by the environment and hence an important indication of the bioactivity of the scaffold used in directing NSCs towards differentiation. Analysis of neurite outgrowth by ImageJ 
program is described in this section. ImageJ is an NIH-released free program that can be downloaded from http://rsbweb.nih.gov/ij/.

1. At the intended time of analysis (multiple time points during differentiation is useful), take at least five random images from each sample. You should study with at least three replicates $(n)$ within each experimental group.

2. Open the image to be analyzed with ImageJ program. Select segmented line in the tabs which allows to track neurites even when they are curved. From shortcuts list, find the shortcut for "Measure and Label." This shortcut is a letter in the keyboard which you can use to measure the length of the neurite you tracked. Besides it labels the track so that you do not measure it twice. After labeling and measuring all neurites in the image you can transfer results to Excel for further analysis such as the total neurite length in the image. Besides, by using the cell counter plug-in, you can count the total number of cells in the image as well as the cells extending neurites.

3. After measuring the total neurite length, total number of cells, and number of cells extending neurites, you can now calculate the average neurite length in that image as well as \% of cells extending neurites. Note that the length measured in ImageJ is in arbitrary unit (au). You can convert this to $\mu \mathrm{m}$ by measuring the scale bar in the image and finding the conversion factor between au and $\mu \mathrm{m}$. By using this conversion factor, you can now express the average neurite length in the image in $\mu \mathrm{m}$ scale.

4. After completing the measurement of all images, take average of random images from the same well and after that take average of different samples of the same experimental group and find the standard deviation within the group.

1. PFA is toxic; weigh and prepare the solution in a fume hood.

2. Gelation properties and bioactivity of different peptides might differ. Hence, it is better to carry out an optimization with different concentrations of peptides for scaffold preparation. Lower concentrations might not lead to gel formation, while too high concentrations result in opaque gels leading to difficulty in observing cells under optical microscope. Besides, the concentration with optimal bioactivity should be determined with such an optimization assay.

3. We use rat fetal NSCs obtained from Invitrogen. These cells are isolated from cortex of embryonic day 14 Sprague-Dawley rats. Seeding density of $5 \times 10^{4}$ cells $/ \mathrm{cm}^{2}$ is suggested for 
these cells to avoid spontaneous differentiation. If using cells from other sources, it is better to optimize seeding density prior to other experiments.

4. Avoid exposing Alamar Blue reagent to light as it is reduced in light which leads to false-positive results.

5. Co-staining of different proteins in same samples is a powerful method for determining \% of different cell types in the same population of cells. In order to carry out co-staining, you need to select primary antibodies from different sources (such as one from mouse, the other from rabbit) and secondary antibodies specific to these primary antibodies should be labelled with different fluorophores. In this case, you can incubate same samples with both primary antibodies at the same time. In the secondary antibody treatment, you should also add both secondary antibodies to the same well. While imaging, you can take merged images showing expression of both proteins.

6. You can also use DAPI or some other fluorescent dyes commercially available for nuclear staining. However, check whether the excitation and emission wavelengths are suitable with your fluorescent/confocal microscope before carrying out staining.

7. Brain lysate preparation: We prepare lysate from frozen (stored at $-80{ }^{\circ} \mathrm{C}$ ) mouse brain. It can also be prepared from fresh tissue. Mince brain with scalpel after weighing. Add $1 \mathrm{~mL}$ of urea buffer to $1 \mathrm{~g}$ tissue, and sonicate with a probe sonicator on ice. Incubate at $95-100{ }^{\circ} \mathrm{C}$ for $5-10 \mathrm{~min}$. Determine the total protein concentration by a method of your choice (we use Bradford method).

\section{Acknowledgments}

B.M. is supported by Scientific and Technological Research Council of Turkey (TUBITAK) grant number 111 M410. M.O.G and A.B.. T. acknowledge support from the Turkish Academy of Sciences Distinguished Young Scientist Award (TUBA-GEBIP).

\section{References}

1. Temple $S$ (2001) The development of neural stem cells. Nature 414(6859):112-117

2. Einstein O, Ben-Hur T (2008) The changing face of neural stem cell therapy in neurologic diseases. Arch Neurol 65(4):452-456

3. Yuan T et al (2013) Human induced pluripotent stem cell-derived neural stem cells survive, migrate, differentiate, and improve neurological function in a rat model of middle cerebral artery occlusion. Stem Cell Res Ther 4(3):73

4. Falk A et al (2012) Capture of neuroepitheliallike stem cells from pluripotent stem cells provides a versatile system for in vitro production of human neurons. PLOS One 7(1) 
5. Thier $\mathrm{M}$ et al (2012) Direct conversion of fibroblasts into stably expandable neural stem cells. Cell Stem Cell 10(4):473-479

6. Ring K et al (2012) Direct reprogramming of mouse and human fibroblasts into multipotent neural stem cells with a single factor. Cell Stem Cell 11(1):100-109

7. Sharma K, Selzer M, Li S (2012) Scar-mediated inhibition and CSPG receptors in the CNS. Exp Neurol 237(2):370-378

8. Toksoz S, Mammadov R, Tekinay A, Guler M (2011) Electrostatic effects on nanofiber formation of self-assembling peptide amphiphiles. J Colloid Interface Sci 356(1):131-137

9. Mammadov B, Mammadov R, Guler M, Tekinay A (2012) Cooperative effect of heparan sulfate and laminin mimetic peptide nanofibers on the promotion of neurite outgrowth. Acta Biomater 8(6):2077-2086

10. Nishida T, Yasumoto K, Otori T, Desaki J (1988) The network structure of corneal fibroblasts in the rat as revealed by scanning electron-microscopy. Invest Ophthalmol Vis Sci 29(12):1887-1890

11. Guler M et al (2006) Presentation of RGDS epitopes on self-assembled nanofibers of branched peptide amphiphiles. Biomacromolecules 7(6):1855-1863

12. Anderson J et al (2009) Osteogenic differentiation of human mesenchymal stem cells directed by extracellular matrix-mimicking ligands in a biomimetic self-assembled peptide amphiphile nanomatrix. Biomacromolecules 10(10):2935-2944

13. Sur S et al (2012) A hybrid nanofiber matrix to control the survival and maturation of brain neurons. Biomaterials 33(2):545-555

14. Ceylan H, Tekinay A, Guler M (2011) Selective adhesion and growth of vascular endothelial cells on bioactive peptide nanofiber functionalized stainless steel surface. Biomaterials 32(34):8797-8805

15. Silva G et al (2004) Selective differentiation of neural progenitor cells by high-epitope density nanofibers. Science 303(5662):1352-1355

16. Marchenko S, Flanagan L (2007) Immunocytochemistry: human neural stem cells. J Vis Exp (7):267

17. Sur S, Newcomb CJ, Webber MJ, Stupp SI (2013) Tuning supramolecular mechanics to guide neuron development. Biomaterials 34 (20):4749-4757

18. Mammadov R, Tekinay A, Dana A, Guler M (2012) Microscopic characterization of peptide nanostructures. Micron 43(2-3):69-84

19. Lendahl U, Zimmerman LB, McKay RD (1990) CNS stem cells express a new class of intermediate filament protein. Cell 60 (4):585-595

20. Caccamo D et al (1989) Immunohistochemistry of a spontaneous murine ovarian teratoma with neuroepithelial differentiation. Neuronassociated beta-tubulin as a marker for primitive neuroepithelium. Lab Invest 60 (3):390-398

21. Matus A (1988) Microtubule-associated proteins: their potential role in determining neuronal morphology. Annu Rev Neurosci $11: 29-44$

22. Svendsen CN, Bhattacharyya A, Tai YT (2001) Neurons from stem cells: preventing an identity crisis. Nat Rev Neurosci 2(11):831-834

23. Pixley SK, Kobayashi Y, de Vellis J (1984) Monoclonal antibody to intermediate filament proteins in astrocytes. J Neurosci Res 12 (4):525-541

24. Rostami A et al (1984) Generation and biological properties of a monoclonal antibody to galactocerebroside. Brain Res 298(2):203-208 